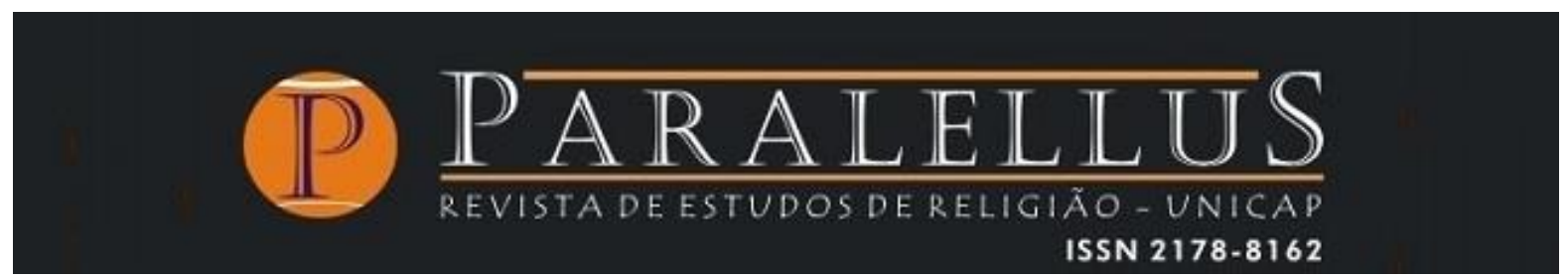

Volume 12 - Número 30

DOSSIÊ: INTERPRETAÇÃO PLURALISTA DAS RELIGIÕES

doi: 10.25247/paralellus.2021.v12n30.p433-447

\title{
A DISPONIBILIDADE E INDISPONIBILIDADE DA SABEDORIA: A DIALÉTICA DA SABEDORIA EM PROVÉRBIOS E JÓ
}

\author{
THE AVAILABILITY AND UNAVAILABILITY OF WISDOM: THE DIALECTICS \\ OF WISDOM IN PROVERBS AND JOB
}

\begin{abstract}
Luiz Alexandre Solano Rossi*
Lucas Merlo Nascimento
\end{abstract}

\section{RESUMO}

O artigo analisa as estratégias literárias utilizadas em Provérbios 1,20-33; 8,1-36; 9,1-6 e Jó 28,1-28 comparando como esses diferentes poemas tematizam a sabedoria a fim de caracterizar a disponibilidade e indisponibilidade dela aos seres humanos. A escolha desses textos se dá por critérios objetivos: 1. Neles, a disponibilidade e os caminhos para encontrar a sabedoria são enunciados; 2. Quanto à datação, os textos são, aparentemente, contemporâneos, datados entre o fim do período de dominação persa e o início da dominação grega; 3. Os textos fazem parte da edição final dos respectivos livros. No caso de Provérbios, no conjunto de poemas em Pv 1-9. No caso de Jó, como edição entre os diálogos de Jó e seus amigos (3-27) e a intervenção divina (38-41); 4. Os textos desempenham um papel literário-teológico importante em sua localização no livro. Por isso, analisa também a função dessa caracterização na edição dos livros de Provérbios e Jó. Por fim, a análise da dialética literária da disponibilidade e indisponibilidade da sabedoria contribui a para compreensão da mesma dialética na experiência humana.

Palavras-chave: Bíblia Hebraica; Literatura sapiencial; Análise literário-teológica.

\section{ABStRACT}

\footnotetext{
* Doutor em Ciências da Religião pela Universidade Metodista de São Paulo. Professor da Pontifícia Universidade Católica do Paraná e do Centro Universitário Internacional (UNINTER).

** Doutorando em Teologia pela PUC-PR. Mestre em Ciências da Religião, com ênfase em Literatura e religião no mundo bíblico, pela Universidade Metodista de São Paulo (UMESP).
} 
The article analyzes the literary strategies used in Proverbs 1:20-33; 8:1-36; 9:1-6 and Job 28:1-28 comparing how these different poems thematize wisdom in order to characterize its availability and unavailability to humans. The choice of these texts is based on objective criteria: 1 . in them the availability and the ways to find wisdom are enunciated; 2 . as for dating the texts are contemporary, dated between the end of the period of Persian domination and the beginning of Greek domination; 3. the texts are part of the final edition of the respective books, in collection of poems in Prov. 1-9 and in Job as an edition between the dialogues of Job and his friends (3-27) and the divine intervention (38-41); 4. The texts play an important literary-theological role in their location in the book. Therefore it also analyzes the function of this characterization in the editing of the books of Proverbs and Job. Finally, the analysis of the literary dialectic of the availability and unavailability of wisdom contributes to an understanding of the same dialectic in human experience.

Keywords: Hebrew Bible; wisdom literature; literary-theological analysis.

\section{INTRODUÇÃO}

O presente artigo tem como objetivo esclarecer as estratégias literárias utilizadas nos textos da tradição sapiencial da Bíblia Hebraica em que a sabedoria é apresentada paradoxalmente como disponível e indisponível ao ser humano, a fim de compreender a função dessa caracterização para os livros de Provérbios e Jó. Para tanto, são abordados os textos de Provérbios 1,20-33; 8,1-36; 9,1-6 e Jó 28,1-28. A abordagem aos textos indicados não se dá por meio de uma exegese exaustiva, antes, por meio do levantamento sumário de dados textuais que indicam a disponibilidade e indisponibilidade da sabedoria. A análise fundamenta-se em exegetas de tradição católica e protestante. A escolha desses textos se dá por critérios objetivos: 1. Neles, a disponibilidade e os caminhos para encontrar a sabedoria são tematizados; 2 . Do ponto de vista da datação, os textos são, aparentemente, contemporâneos; 3. Os textos fazem parte da edição final dos respectivos livros; 4. Os textos desempenham um papel literário-teológico importante em sua localização no livro.

Os capítulos iniciais do livro de Provérbios (1-9), assim como o final (31) são as partes mais recentes do livro. Servem como "introdução" à coletânea dos provérbios populares (10-30), conforme Líndez (2011, p.66-67). Descrevendo de forma geral a formação do livro, Lorenzin (2020, p.39) propõe:

Num primeiro momento, no período pré-exílico, existiam as coleções de provérbios populares em relação à família e ao clã. Num segundo momento, no final do século VIII a.C., sob o reinado de Ezequias $(25,1)$, foram encorajadas a coleta, a reprodução, a adaptação e a 
ampliação do material antigo. O terceiro momento diz respeito à redação do editor, provavelmente ocorrida no período pós-exílico (IVIII a.C.), e seguramente antes da formação do livro do Eclesiástico ${ }^{1}$ (por volta do ano 190 a.C.), que em 47,17 faz referência a Pv 1,6. O redator final completou o livro acrescentando Pv 1-9 como introdução, e 31,10-31 como conclusão.

Konrad Schmid (2013, p.231) argumenta que Pv 1-9 pode ser compreendido a partir do pano de fundo da teologia de Isis, propagada pelos ptolomeus, corroborando a datação do texto no período helenista. Para ele, Pv 1-9 apresenta-se como sabedoria em roupagem teológica, já desenvolvida. Os sinais desse desenvolvimento são: 1.0 caminho para a sabedoria passa pelo temor a $\mathrm{YHWH}$; 2. A sabedoria encontra-se personificada, inclusive presente na criação do mundo; 3. A visão otimista de retribuição daquele que possui a sabedoria, possivelmente sob influência da teologia deuteronomista (SCHMID, 2013, p.232-233).

Pinto (2018, p. 25-26) identifica Pv 1-9 com o período persa tardio ou helenista. Para ele, apontam nesta direção os paralelos entre a figura da mulher estrangeira em Pv 19 e o perigo do casamento com mulheres não judias em Esdras e Neemias (Ed-10, Ne 13). Também a forma de instrução que se encontra em Pv 1-9, segundo o autor, aproxima-se da retórica greco-romana. Por isso "é plausível pensar que o(s) redator(es) de $\operatorname{Pr}$ 1-9 tenha(m) querido redigir um texto impregnado de tradições judaicas, mas, no que se refere à estrutura, em forma helenística ${ }^{2}$." O autor indica uma datação "provavelmente por volta de 350 a.C.: no final do período persa e antes, certamente, do escrito de Coélet (cerca de 250 a.C.), do qual ignora as angústias existenciais e religiosas" (PINTO, 2018, p.26). Especificamente sobre a relação dos poemas de $\mathrm{Pv}$ 1,8-9,18 e sua relação interna e com o restante do livro, Pinto (2018, p.13) escreve:

Ao prólogo segue-se a primeira coleção $(1,8-9,18)$, que apresenta uma divisão interna diferente em relação às outras: não se ilustram simples ditos separados um dos outros e/ou apenas levemente ligados ao contexto do capítulo em que se encontram, mas se oferece uma série

1 A tradução da obra de Lorenzin para a Língua Portuguesa grafa "Eclesiastes", provavelmente equívoco do tradutor.

$2 \mathrm{O}$ autor se refere especificamente aos poemas encontrados em 1,8-19; 2,1-22; 3,1-12; 3,21-35; 4,1$9 ; 4,10-19 ; 4,20-27 ; 5,1-23 ; 6,20-35 ; 7,1-27$. A esses se acrescentam os poemas de personificação da sabedoria (1,20-33; 8,1-36; 9,1-6.13-18) que lhes são complementar (PINTO, 2018, p.13-14)

Paralellus, Recife, v. 12, n. 30, mai./ago. 2021, p. 433-447 
de poemas em estreita relação com os capítulos do livro da mesma coleção e com o resto do livro.

Mesmo uma postura exegética mais conservadora, reconhece-se o papel do editor final e sua localização no período persa ou helenista, que teria permitido à obra permanecer debaixo do nome de Salomão, que seria o autor principal (WALTKE, 2011, p.77). Kidner (1980, p.22-27) também entende que a atribuição a Salomão em Pv 1,1 seja editorial. Discute o pano de fundo canaanita de Pv 8 e 9, que apontaria para certa antiguidade, contra a tendência de atribuir ao período persa ou grego, mas reconhece que os caps. 1-9 foram colocados por um redator final.

Assim, pode-se notar que os poemas contidos em Pv 1-9 fazem parte da edição final do livro e mantém, portanto, uma função estrutural em relação ao mesmo.

Konrad Schmid (2013, p.234) localiza Jó 28 no período helenístico, na última edição do livro e reconhece sua "posição peculiar" no livro junto aos discursos de Eliú em Jó 32-37. Para ele, esses textos tenderiam a trazer novamente o livro de Jó a uma "ortodoxia moderada". Neste sentido também apontam Rossi e Nascimento (2021, p.10). Especificamente "O hino da sabedoria em Jó 28, que, anexado a Jó 27, aparece construído como discurso de Jó, afasta a possível compreensão de que nos diálogos Jó estaria recusando totalmente sabedoria e temor a Deus" (SCHMID, 2013, p.235).

Jean Leveque (1987, p.8) aponta na mesma direção quanto a datação, assim como destaca a função editorial do cap. 28:

O redator anônimo (IV-III séculos), que o inseriu em seu lugar atual, deu provas de gosto muito seguro. Sem dúvidas, ele quis concluir as discussões de Jó e de seus amigos relativizando ousadamente todo saber do homem e todas as suas afirmações: o homem não conhece o caminho da Sabedoria, e esta não se encontra na terra dos vivos (vv.12s, 20s). O poema de Jó 28 lança, assim, uma ponte entre os diálogos (4-27) e a segunda metade do poema, em que Jó, depois de haver protestado e confirmado sua inocência e depois de ter feito a Deus seu último desafio (29-31), verá, por sua vez, contestados seu poder e sua sabedoria ${ }^{3}$. 
Andersen (1984), sem identificar o período histórico, e com ampla discussão sobre a crítica do desenvolvimento histórico do livro, reconhece que Jó 28 não se encaixa bem na continuidade da fala do personagem Jó:

O capítulo 28 é melhor explicado como um tipo de coda entre o diálogo principal e a palavra final de Jó, mas não como parte do próprio pensamento de Jó a esta altura. É um comentário do autor, e quem fala é a pessoa contando a história, não uma das personagens da história (ANDERSEN, 1984, p.51).

Desse modo, tem-se certa convergência por parte dos autores entre o período de redação e a função editorial dos textos de Pv 1-9 e Jó 28, de modo que podem ser compreendidos como reflexão teológica ampla sobre o papel da sabedoria na realidade humana em sua função estrutural-literária nos respectivos livros. Passamos, então, à compreensão dos poemas nos quais a (in-)disponibilidade da sabedoria é tematizada.

\section{A DISPONIBILIDADE DA SABEDORIA: PV 1,20-33; 8,1-36 E 9,1-6}

Os poemas de Pv 1,20-33; 8,1-36 e Pv 9,1-6 apresentam-se como textos nos quais a sabedoria é personificada e clama por ser ouvida, e são intercalados aos poemas de instrução iniciados com "Filho meu" encontrados em 1,8-19; 2,1-22; 3,1-12; 3,21-35; $4,1-9 ; 4,10-19 ; 4,20-27 ; 5,1-23 ; 6,20-35 ; 7,1-27$.

O texto de Pv 1,20-33 apresenta-se como um breve poema no qual a sabedoria ${ }^{4}$ grita a fim de que os ingênuos e insensatos ouçam sua voz. A estrutura do poema e sua linguagem apresentam-se com características de discurso profético de denúncia (v.24-25) e ameaça (v.26-31), recoberto pela linguagem sapiencial (v.23.32-33, cf. ainda LORENZIN, 2020, p.41; PINTO, 2018, p.38-39; MURPHY, 2002, p.10). Tem-se uma divisão em 4 partes do poema, a saber: 1,20-21 um convite no qual a sabedoria apresenta-se personificada e clama por ser ouvida; 1,22-25 questionamento, convite e acusação aos homens; 1,26-31 juízo e 1,32-33 exortação final.

4 Quanto ao uso plural ḥokmôt como expressão da personificação da sabedoria, Fox (2008, p.96) diz que a forma plural é usada com verbo no singular refere-se a um indivíduo. Kidner (1984, p.58, nota 3 ) indica ser uma forma fenícia de singular ou plural hebraico. No último caso, seria para expressar intensidade e plenitude, sendo regido pelo verbo no singular. 
A publicidade e disponibilidade da sabedoria encontra-se na introdução ao poema, nos v.20-23, em terceira pessoa, que introduz o discurso da sabedoria. Nele podemos encontrar ações que a sabedoria personificada faz: grita (tārōnnâ - v.20), dá sua voz (tittēen qôlāh - v.20), clama (hōmiyyôt - v.21), chama (tiqrā' - v.21, também no v.24, em primeira pessoa), diz (tómēr - v.21). Sua publicidade ainda é reforçada pelos locais nos quais a sabedoria personificada faz suas ações, todos eles locais públicos e visíveis: na rua (hûș - v.20), praça (rəhōobôtt - v.20), alto (rō’š -v.21), entrada das portas (pithê šəā'rîm - v.20), na cidade ('îr - v.21 - v.20).

A publicidade da sabedoria pode ser encontrada também no poema de 8,1-36, que pode ser estruturado da seguinte forma: 8,1-3 sabedoria fala em público; 8,4-11 admoestação pública; 8,12-21 autoapresentação da sabedoria; 8,22-31 a sabedoria e a criação; 8,32-36 exortação final em forma de bem-aventurança.

Uma vez mais a atenção voltada para a introdução do poema, em terceira pessoa, leva-nos à dimensão pública e disponível da sabedoria. Nos v.1-3 tem-se repetidas as ações que apontam para sua publicidade: chamar (tiqrā' - v.1), dar sua voz (tittēn qôlāh - v.1), gritar (tārōnnâ - v.3), reforçada ainda pelo início do discurso em primeira pessoa, com o uso do verbo chamar ('eqrā'- v.4).

Neste segundo poema destacam-se ainda mais os locais públicos a partir dos quais a sabedoria personificada faz ouvir sua voz: no topo das alturas (rô'š mərômîm - v.2), ao lado do caminho ('ălê- $\underline{-} a \bar{r} e \underline{k}-\mathrm{v} .2$ ), nas encruzilhadas, veredas (nəțîbôt $\underline{t}$ - v.2), junto às portas (ləyad-šə‘̄âim - v.3), na abertura da cidade (p̣̂i-qāret - v.3), no acesso das entradas (məộô' pəotāhîim - v.3).

Esse poema, especificamente, ainda desenvolve o tema da disponibilidade da sabedoria ao apresentá-la como presente na ordem criacional (v.32-36). Nessa parte, não apenas ela é apresentada como antecedente aos demais atos criadores (v.2226a), como também presente no restante da criação (v.26b-31), destacando-se dua presença entre os "filhos de adam" (v.31b).

Por último, o breve poema de 9,1-6, no qual a sabedoria personificada mostra-se como pública e disponível, estrutura-se em duas partes: 9,1-3 apresenta os atos de 
preparação do banquete da sabedoria; 9,4-6 convite ao banquete. Também neste a publicidade da sabedoria pode ser notada no início do poema, especificamente no v. 3: "envia suas servas a chamar (tiqrā'), sobre os topos dos altos ('al-gappê-mərōmê) da cidade (qāreț)".

Olhando-se os três poemas em conjunto, observa-se um vocabulário comum para a publicidade e disponibilidade da sabedoria, que pode ser classificado em:

1. Verbos e expressões que apontam para a ação oral de chamar e seus cognatos: grita (tārōnnâ, usado predominantemente com significado de "gritar de júbilo", cf. Lv 9,24; Dt 32,43; Jó 38,7; SI 20,6, Is 54,1); dá sua voz (tittēn qôlāh, cf. Gn 45,2; Pv 2,3); clama (hōmiyyôt, cf. SI 46,6; 55,18; Is 17,12); chama (tiqrā', cf. Pv 2,3; Jó 14,15; Is 55,$5 ; 58,9 ; \operatorname{Lm~2,22).~}$

2. Substantivos que apontam para lugares públicos e de grande circulação: rua (hûș, cf. Jó 18,7; Pv 7,12; Ct 8,1; Is 42,2; Na 2,5); praça (rəḥōbôt, cf. Pv 7,12; Lm 2,11-12; $\mathrm{Na} 2,5$; Zc 8,4); cidade ('îr, cf. Gn 34,28, em oposição ao campo); entrada das portas (pithêe šəā'rîm, cf. Is 26,2; Ez 21,27); ao lado do caminho ('ălê-d̄ārek, cf. Gn 49,17), nas encruzilhadas, veredas (nətîibôt, cf. Jó 38,20; Is 58,12; Jr 18,15), junto às portas (ləyad-šəəārîm, cf. expressão aproximada "junto ao caminho" - SI 140,6), na abertura

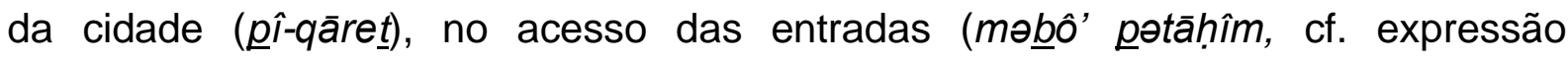
aproximada "acesso da cidade" Jz 1,24-25). Conforme Pinto (2018, p.38.93), alguns desses são lugares para tomar decisões, administrar a justiça e governar a cidade (Jr 17,19-20; Rt 4,10-11; Jó 29,7-25). Descrevem também uma realidade urbana de grande circulação ${ }^{5}$. Em concordância, Murphy (2002, p.49) indica a "abertura ou portões da cidade" como "o coração do comércio, da atividade jurídica e do intercâmbio social" 6 . Waltke (2011, p.274) aponta para as "praças públicas" como lugar de transações comerciais e reuniões públicas, em contraste com as ruas estreitas e Fox (2008, p.266) declara que os portões da cidade, são o centro da vida social, comercia e legal.

5 Nota-se o uso tanto de 'îr como qeret como referência à cidade. O substantivo qeret é usado apenas em textos poéticos sapienciais: Pv 8,3; 9,3.14; 11,11; Jó 29,7.

6 Tradução nossa: "the heart of commerce, judicial activity, and social exchange." 
3. Substantivo que apontam lugares destacados e visíveis devido à altitude: alto (rô'š, cf. Ex 24,17; Nm 20,28; Jz 9,7); no topo das alturas (rô'š mərômîm, cf. Is 33,16); sobre os topos dos altos ('al-gappê-mərōmê, cf. 2Rs 19,23, par. Is 37,24) da cidade (qāreț).

Tendo observado essas características textuais, pode-se compreender ao menos quatro estratégias literárias que os poemas usam para indicar a publicidade e disponibilidade da sabedoria: o uso da personificação, a indicação de ações de chamar, a localização pública da sabedoria e o discurso direto no qual a própria sabedoria toma a palavra. Sobre a personificação, ainda que possa ser visto não apenas como estratégia literária, mas também como uma carga teológica, o uso teológico não elimina sua função poética. Sobre isso, Líndez afirma (2011, p.55):

Parece que a pura abstração poética é muito pouco, pois o recurso à personificação da sabedoria não é um mero jogo da fantasia do artista, cujo conteúdo permanece em sua imaginação. A subsistência própria, mesmo que dependente de Deus, vai longe demais, pois na realidade não se tem em vista uma pessoa. Devemos, pois, entender por personificação da sabedoria um termo médio entre a pura fantasia poética e a realidade de uma verdadeira pessoa.

As estratégias da indicação das ações e a localização pública da sabedoria ficam claras pelo vocabulário utilizado, tanto os verbos e locuções verbais, quanto nos substantivos e expressões nominais, acima explorados. Por último, note-se o uso do discurso direto. $O$ discurso direto pode ser visto pela mudança de pessoas, passando da terceira pessoa, nas introduções aos poemas $(1,20-21 ; 8,1-3 ; 9,1-3)$ para a primeira pessoa, na qual a própria sabedoria passa a falar $\left(1,22-23 \mathrm{~s}^{7} ; 8,4 \mathrm{~s} ; 9,4 \mathrm{~s}^{8}\right)$. O uso do discurso direto nesses poemas reforça a proximidade da sabedoria, que, no conjunto de Pv 1-9, soma-se ao uso da expressão "filho meu" nos poemas de "instrução", na qual o mestre/pai conduz o aprendiz/filho nos caminhos da sabedoria9 .

7 O v.22 dirige-se à segunda pessoal do plural, os néscios, corroborando-se como fala da própria sabedoria na primeira pessoa do singular, no v.23. Cf. PINTO, 2018, p.38

8 De fato, a mudança para o discurso da sabedoria em Pv 9,1-6 só se explicita no v.5, no qual o uso da primeira pessoa torna-se claro. O v.4a pode ser a convocação das servas da sabedoria, e o v.4b, finalmente, a introdução ao discurso direto, que finalmente se inicia no v.5.

9 Ao comentar Pv 1,20-33, Waltke (2011, p.272) propõe que a passagem do discurso direto nos ditos "filho meu" para o discurso indireto nos poemas da sabedoria personificada apontariam para um afastamento no tempo do julgamento, no qual "a distância tomará o lugar da intimidade; a separação substituirá o envolvimento". Porém, deve-se levar em conta que o discurso indireto serve para introduzir o discurso da sabedoria personificada, diferenciando-a da voz daquele que ensina ao "filho meu". 


\section{A INDISPONIBILIDADE DA SABEDORIA: JÓ 28,1-28}

Conforme já visto, é possível que o poema de Jó 28 seja contemporâneo aos textos de Pv 1-9. Chama a atenção que também tematize o tema da disponibilidade da sabedoria. Porém, em sentido inverso a Provérbios, em Jó a sabedoria é descrita como oculta e indisponível.

A estrutura do poema baseia-se na repetição da pergunta nos v. 12 e 20 (LEVEQUE, 1987; HEINEM, 1982, p.91; ANDERSEN, 1984, p.222-223): "E a sabedoria onde é encontrada? / e onde está o lugar do discernimento?". Essa pergunta divide o poema em 3 partes: 28,1-11 a capacidade humana consegue explorar a pedra preciosa mais oculta, porém... 28,12-19 a capacidade humana desconhece a sabedoria; 28,20-28 Deus conhece a sabedoria e, para o ser humano, sabedoria é temor a Deus.

A descrição explicita da ocultação e indisponibilidade da sabedoria concentra-se na segunda e terceira parte do poema, especificamente após a pergunta dos v.12 e 20, apresentando-se como resposta imediata. A própria pergunta apresenta-se como estratégia literária que tematiza a indisponibilidade da sabedoria: pergunta-se por aquilo que não está disponível. Interessante notar que, enquanto em Pv 1-9 a própria sabedoria clama, grita e chama, em Jó 28 é o narrador que pergunta pela sabedoria. Comparando Jó 28 com Pv 8, Schökel (1971, p.132) propõe que "em Pv 8 o ponto de partida é o oposto, a sabedoria toma a inciativa de buscar o ser humano e por ele o ser humano a pode encontrar"10

Segue-se à pergunta as respostas. No v. 13, explicita-se o duplo desconhecimento $\mathrm{e}$ ocultação da sabedoria em relação ao ser humano: este desconhece seu preço ('erkāh ${ }^{11}$ ) e não está disponível na terra dos viventes ('ereș haḥayyîm). O tema do "preço da sabedoria" desenvolve-se nos v.15-19, enquanto sua indisponibilidade geográfica no v.14. Após a segunda pergunta, no v.20, a resposta do v. 21 reforça a

10 Tradução nossa. Original: "En Pv 8 el punto de partida es el opuesto, la sabiduría toma la iniciativa de buscar al hombre, y por ello el hombre la puede encontrar"

11 A tradução grega corrigiu "preço" ('rk) por "caminho" (drk). Sobre isso, conferir BIBLIA DE JERUSALÉM, 2006, p.836, nota. d.; BHS, 2009, p.1255, aparato crítico. Ainda que a correção faça sentido, o texto hebraico parece seguir a lógica dos versos seguintes (v.14-19), cf. REYBURN, 1992, p.508; ANDERSEN, 1984, p.226. 
indisponibilidade da sabedoria às pessoas: encoberta (ne'elmâ) aos olhos de todo vivente (ḱl-hāy), escondida (nistārâ) às aves dos céus ('ôp haššāmayim).

A indisponibilidade da sabedoria pode ser notada também por meio da comparação entre as duas primeiras partes do poema (v.1-11+12-19). Entre essas, é comparada a ação de buscar minérios (v.3-5.7-9), com a busca pela sabedoria. Enquanto aqueles, com muito esforço, podem ser encontrados, esta é indisponível ao ser humano. Além da comparação da ação de buscar, reforça-se ainda por meio da comparação do valor incalculável da sabedoria em relação aos minérios de alto valor (v.1-2.5.15-19). Assim, não apenas encontrar a sabedoria seria humanamente impossível, como também precificá-la.

Interessante estratégia literária utilizada em Jó 28 é o uso da personificação, quando comparada a Pv 1-9. Em Jó 28 a sabedoria não é personificada, antes, os lugares nos quais ela poderia estar, mas não se encontra, são (cf. CLINES,2006, p. 917). A personificação pode ser notada pelos discursos diretos. São personificados o abismo (təhôm - v.14), o mar (yām - v.14), a perdição ('ăbaddôn - v.22) e a morte (māwet $\underline{t^{12}}$ v.22). São lugares ocultos ao ser humano ${ }^{13}$. Essas referências transcendem a "localização geográfica", sendo associados ao "mundo dos mortos" (šə'ôl - MARTINACHARD, 2015, p.55.60) e possuindo um caráter simbólico-religioso ${ }^{14}$. Terrien (1994, p.219-220) explica:

No ambiente cultural do Oriente clássico, essas alusões não podem ser tomadas como simples adornos poéticos. O poeta faz alusões às práticas rituais dos egípcios, dos fenícios e dos mesopotâmicos. Eis o homem à procura do segredo de seu destino. Ele oferece o preço mais exorbitante para adquiri-lo. [...] O Abismo e a Morte, símbolos cósmicos, são tão estranhos à sabedoria como a tecnologia do homem e o rito dos sacerdotes. No começo da terceira estrofe ele põe em cena

12 Reforçando a personificação da morte, o Targum traduz como "anjo da morte" (ml'k mwt', cf. POPE, 2008, p.205)

13 Andersen (1984, p.226) comenta: "O argumento é que não pode ser obtida do mundo, nem dos mais primevos e elementares poderes da natureza. Tehom e Yam, o original caos aquático da criação."

14 Martin-Achard (2015, p.55.60) levanta as seguintes referências nas quais as expressões são usadas associadas aos šə'ôl: para təhôm: SI 42,7; 71,20; 77,17; Ex 15,5.8 etc; para yām: SI 46,3; Lm 2,13; Jó 26,5ss; 'ăbaddôn SI 88,12; Jó 26,6; 28,22; 31,12; Pv 15,11. Também G. Gerleman associa o šə'ôl ao 'ăbaddôn e māwet (JENNI; WESTERMANN, 1985, Tomo II, col.1056). Andersen (1984, p.226) comenta: "Se Abadom e a Morte são poderes elementares que correspondem aos caos, então não devemos achar no v. 22 uma contradição da idéia de que aquilo que não está disponível "na terra dos viventes" (v. 13, que é outro contrapeso ao v. 22) talvez seja encontrado no Seol, sem mencionar uma polêmica contra a necromancia." 
as divindades da morte, assim como no começo da segunda estrofe, por um instante, fez falar os deuses do abismo aquoso...

Nessas referências geográfico-simbólicas, em comparação com os poemas de Pv 19, os lugares na qual a sabedoria está ou é procurada apresentam-se em contraste flagrante: de lugares públicos, de grande circulação, conhecidos e visíveis, a lugares ocultos, difíceis e simbólico-religiosos nos quais, nem lá, a sabedoria se encontra.

A última estratégia literária para compreender a descrição da indisponibilidade da sabedoria, em comparação a Pv 1-9, especificamente Pv 8,1-36, é a tematização da sabedoria em relação à criação. Enquanto em $P v 8$ o tema apresenta-se em função da disponibilidade e explicitação da sabedoria na criação, seja como sua antecessora, seja como presente na mesma, em Jó o próprio Deus é quem perscruta a sabedoria na criação $(28,23-27)$, tema que é desenvolvido nos discursos finais de Deus em Jó $38-41^{15}$.

\section{DISPONIBILIDADE E INDISPONIBILIDADE: A FUNÇÃO LITERÁRIA DA SABEDORIA EM PROVÉRBIOS E JÓ E A DIALÉTICA DA VIDA HUMANA}

Após notar as aproximações temporais e temáticas de Pv 1-9 e Jó 28, perguntamos sobre as diferentes e antagônicas caracterizações da sabedoria em ambos e sua relação com a composição com os respectivos livros. Já foi observado que tais textos fazem parte da composição final dos livros. Portanto, partimos de sua forma final para compreender sua função estrutural e, ao comparar ambas, deduzir do conjunto do corpus literário sapiencial as percepções literário-teológicos sobre a sabedoria.

Já se destacou a função de Pv 1-9 como introdução ao livro de Provérbios. A personificação da sabedoria em discurso direto, assim como a retórica instrucional presente nos poemas de Pv 1-9 servem para introduzir as coletâneas de sabedoria popular presentes em $\mathrm{Pv}$ 10,1-31,9.

15 Sobre essa relação entre Jó 28 e o derradeiro discurso divino, Terrien (1994, p.29) escreve: "Entretanto, a sua linguagem e o seu estilo apresentam afinidades estreitas com os discursos de lahweh [...] Ele parece ser, pois, uma composição do próprio poeta, colocada por um membro da escola jobiana em sua posição atual, na forma de 'gradual' ou de preparação para a teofania (caps. 38ss)." 
Exatamente na compreensão desse nexo encontra-se a resposta literário-teológica para a disponibilidade e explicitação da sabedoria em Pv 1-9. Isso porque em Pv 1031,9 tem-se a coletânea de ditos e sentenças proverbiais populares, fruto da experiência cotidiana e comum, da qual deriva a sabedoria experiencial. Assim, por meio da compreensão dessa sabedoria prática, empírica, observável, deduz-se a explicitação da sabedoria. Uma vez que a sabedoria pode ser observada na experiência comum do ser humano, é como se ela clamasse constantemente aos seres humanos para ser observada e seguida. A explicitação do conjunto de comportamento humano, conforme encontrado nos provérbios práticos de Pv 10-31,9, equivale a publicidade da sabedoria personificada, que grita constantemente em lugares públicos.

Já em Jó 28 o contexto literário muda, alterando-se, também, a percepção quanto à sabedoria. Jó 28 serve como invólucro dos diálogos entre Jó e seus amigos sobre a natureza e razão do sofrimento de Jó. Sobre isso, Leveque (1987, p.51) esclarece:

O papel de Jó 28 não se reduz, pois, ao de simples interlúdio. Ao
inserir o poema neste lugar, o autor quis, certamente, concluir o
diálogo de Jó com seus amigos; mas fê-lo propondo, por sua vez, uma
tese radical, que rejeita definitivamente a teologia demasiado curta na
visão dos visitantes. Esta crítica das pretensões da sabedoria atinge,
aliás, o próprio Jó, que, por seu turno, tentou abrir para si caminho a
nível das expressões humanas. (LEVEQUE, 1987, p.51) Assim, a indisponibilidade da sabedoria em Jó 28 serve como certa resposta editorial ao debate entre Jó e seus amigos sobre a suposta culpa de Jó por seu sofrimento (Jó 3-27). Não apenas isso, como também introduz os discursos finais de Deus (38-41). Enquanto resposta ao debate, Jó 28 tira da "terra dos viventes" a possibilidade de encontrar a razão total pelos dissabores da vida humana. Nesta perspectiva, Schwienhorst-Schönberger (2011, p.142) escreve: "Quem pode penetrar filosoficamente de tal maneira na horrível situação de Jó, a ponto de mostrar um caminho de compreensão e interpretação?". Essa perspectiva condiz com o prólogo narrativo do livro (Jó 1-2), no qual encontra-se a razão do sofrimento nas cenas celestiais (1,6-12; 2,1-6) e não nas terrenas (1,1-5.13-20; 2,7-13). Desse modo, a indisponibilidade da sabedoria em Jó 28 vincula-se à tentativa humana frustrada de dar resposta final ao sofrimento humano (Jó 3-27), diante do mistério da vida (Jó 3841). 
Desse modo, a dialética da disponibilidade e indisponibilidade da sabedoria presente nos usos literários em Provérbios e Jó vincula-se às diferentes formas de tematizar a sabedoria na experiência humana. Se por um lado o livro de Provérbios apresenta uma sabedoria prática, empírica, funcional e essa pode ser apreendida pela observação, pelo cotidiano, pelo conselho dos mais velhos, sendo sabedoria disponível, por outro, em Jó, a sabedoria enquanto tentativa de domesticação da realidade, de explicação dos mistérios da vida, apresenta-se como indisponível e oculta ao ser humano, cabendo a este, no mistério de sua existência, abrir mão das tentativas de elaborar sistemas totais de explicação de sua condição finita.

$\mathrm{Na}$ trilha dessas sapiencialidades encontra-se o temor a Deus (yir'at 'ădōnāy/YHWH Pv 1,29; 8,13; Jó $28,28^{16}$ ), o respeito pelo mistério do dom da existência, que nos conduz a observar e cuidar da vida em sabedoria prática, sem, contudo, arrogar-se ao domínio da mesma, em sabedoria total ${ }^{17}$.

\section{CONSIDERAÇÕES FINAIS}

O desenvolvimento literário-teológico da sabedoria na Bíblia Hebraica passa pela compreensão não apenas das diferentes formas literárias que a sapiência bíblica possui, ou da variedade de fenômenos que investiga, desde a arte da prática e do bem viver a partir das observações cotidianas até as especulações sobre o sentido da vida e do sofrimento, como também pela forma com que tematiza a própria sabedoria, como uma espécie de "metadiscurso".

Nos textos de $\mathrm{Pv}$ 1,20-33; 8,1-36 e 9,1-6 e Jó 28,1-28, esse metadiscurso em forma poética apresenta a sabedoria como disponível (Provérbios) e indisponível (Jó) ao ser humano. Essa dialética da sabedoria dá-se pela função que esses textos desempenham nos livros, enquanto pertencentes à edição final destes. No conjunto da sabedoria bíblica, essa dialética também aponta para a experiência humana que ora conhece e desenvolve sabedoria prática, ora não pode lidar com os mistérios da vida.

16 Conferir ainda Pv 1,$7 ; 9,10 ; 10,27 ; 14,27 ; 15,33 ; 19,23 ; 22,4 ; 31,30$.

17 Sobre o temor a Deus como sabedora acessível ao homem e a sabedoria inacessível enquanto controle da vida, cf. HEINEM, 1982, p.93 


\section{REFERÊNCIAS}

ANDERSEN, Francis I. Jó: introdução e comentário. São Paulo: Vida Nova, 1984. (Série Cultura Bíblica)

BHS. Bíblia Hebraica Stuttgartensia. Stuttgart: Barueri: Deutsch Bibelgesellschaft: Sociedade Bíblica do Brasil, 2009.

BIBLEWORKS. BibleWorks 10. 2015. [software]

BÍBLIA DE JERUSALÉM. Bíblia de Jerusalém: nova edição revista e ampliada. São

Paulo: Paulus, 2006.

CLINES, D. J. A. Word Biblical Commentary: Job 21-37. Nashville: Thomas Nelson Publishers, 2006.

FOX, M. V. Proverbs 1-9: A new translation with introduction and commentary. New Haven; London: Yale University Press, 2008. (Anchor Yale Bible Commentary)

HEINEM, Karl. O Deus indisponivel: o livro de Jó. São Paulo: Paulinas, 1982.

JENNI, Ernst; WESTERMANN, Claus. Diccionario Teologico Manual del Antiguo Testamento. Madrid: Cristiandad, 1985. [Tomo II]

KIDNER, Derek. Provérbios: introdução e comentário. São Paulo: Vida Nova, 1980. (Série Cultura Bíblica)

LEVEQUE, Jean. Jó: o livro e a mensagem. São Paulo: Paulinas, 1987. (Cadernos Bíblicos) LíNDEZ, José Vílchez. Sabedoria e sábios em Israel. São Paulo: Loyola, 2011. (Coleção bíblica Loyola).

LORENZIN, Tiziano. Livros Sapienciais e Poéticos. Petrópolis: Vozes, 2020. (Introdução aos Estudos Bíblicos).

MARTIN-ACHARD, Robert. Da morte à ressurreição segundo o Antigo Testamento. Santo André, SP: Academia Cristã, 2015.

MURPHY, R. E. Word Biblical Commentary: Proverbs. Dallas: Word Inc., 2002.

ORTIZ, Pedro. Dicionário de hebraico e aramaico bíblicos. São Paulo: Loyola, 2010.

PINTO, Sebastiano (org). Provérbios: introdução, tradução, comentário. São Paulo: Loyola, 2018. (Coleção bíblica Loyola).

POPE, M. H. Job: Introduction, translation, and notes. New Haven; London: Yale University Press, 2008. (Anchor Yale Bible Commentary)

REYBURN, William D. A handbook on the book of Job. New York: United Bible Society, 1992. (UBS Handbook Series).

ROSSI, Luiz Alexandre Solano; NASCIMENTO, Lucas Merlo (orgs). O livro de Jó: leituras e reflexões. São Paulo: Recriar, 2021.

SCHMID, Konrad. História da Literatura do Antigo Testamento: uma introdução. São Paulo: Loyola, 2013. (Coleção bíblica Loyola). 
SCHWIENHORST-SCHÖNBERGER, Ludger. Um caminho através do sofrimento: o livro de Jó. São Paulo: Paulinas, 2011.

TERRIEN, Samuel. Jó. São Paulo: Paulus, 1993. (Grande Comentário Bíblico)

WALTKE, Bruce K. Provérbios: volume 1, capítulos 1 a 15. São Paulo: Cultura Cristã, 2011. (Comentários do Antigo Testamento) 